\title{
EDITORIAL
}

\section{Tracheostomy in children: an ancient procedure still under debate}

\author{
Angelo Barbato, Laura Bottecchia and Deborah Snijders
}

$\mathbf{T}$ racheostomy is one of the oldest surgical procedures reported in ancient medicine books. It became widely used in the 19th century during the diphtheria epidemics in Europe, and then in the 20th century following a series of devastating poliomyelitis epidemics in the 1950s [1-3]. Around the turn of the 20th century, JACKSON [4] standardised the indications for tracheostomy, the technique itself and the instruments used; he developed anatomically correct tracheostomy tubes and paved the way for further improvement of the technique.

The role of tracheostomy in the ventilatory management of the critically ill adult has been endorsed by the American College of Chest Physicians to improve patients' comfort, to reduce the incidence of pneumonia and to facilitate respiratory weaning [5]. Adults that are clinically stable and necessitate prolonged mechanical ventilation have an indication for tracheostomy [5]; patients with acute respiratory failure, acute exacerbations of chronic pulmonary disease, coma and neuromuscular disorders may also require it $[6,7]$.

While tracheostomy in adults is accepted, in children it is perceived as an aggressive procedure, but over time the indication in paediatrics has changed from an emergency procedure during diphtheria and poliomyelitis epidemics into aid for children dependent on assisted ventilation. In children the most frequent indications are upper airway obstruction (craniofacial malformations, craniofacial and laryngeal tumours, and obstructive sleep apnoea), laryngotracheal abnormalities (bilateral vocal cord paralysis, laryngeal obstruction, severe tracheomalacia and subglottic stenosis due to intubation in premature infants), need for long term ventilation (irreversible neuromuscolar conditions and central nervous system conditions), chronic respiratory disease (bronchopulmonary dysplasia in children aged 1 yr or younger) and failure of extubation [8-13].

Data on the incidence of tracheostomy in ventilated children are lacking: in a Canadian survey tracheostomy is referred in less than $1.5 \%$ of ventilated children [14], and LEWIS et al. [15], in a data analysis of 2,521 hospitals in the USA, refer a rate of 6.6 children per 100,000 child-years. In ventilated adults, incidence of tracheostomy varies from 10 to $24 \%$ depending on the case series $[6,7]$.

Dept of Woman and Child Health, Padua General Hospital, University of Padua, Padua, Italy.

CORRESPONDENCE: A. Barbato, Dept of Woman and Child Health, Padua General Hospital, University of Padua-Italy, Via Giustiniani 3, 35128 Padova, Italy. E-mail: barbato@pediatria.unipd.it
Optimal timing for tracheostomy in children is controversial, outweighing the risk of the procedure and the expected benefits, which include the reduction on duration of mechanical ventilation, stay in the intensive care unit (ICU) and hospital, and the decrease in morbidity and mortality [7]. Surveys in ventilated adult indicate that tracheostomy should be performed medially at 9-13 days of mechanical ventilation [16]. In ventilated children, the option of tracheostomy is suggested later on, after 21-28 days of mechanical ventilation. An explanation for this delay can be the more rapid resolution of acute respiratory distress syndrome in children compared to adults $[6,17]$.

In the 2-yr longitudinal multicentre study involving 22 Spanish hospitals by PÉREZ-RUIZ et al. [13] in this issue of the European Respiratory Journal, indications, duration and complications are reported in 249 tracheostomised children, aged between 1 day and 18 yrs at the beginning of the study. To our knowledge this is the largest case series published in the English literature on this topic. In these patients, the main reason for tracheostomy was prolonged ventilation, required as a result different underlying conditions; the median age of children undergoing the procedure was 6 months, with a wide range of age (from 1 day to 17 years). 92 children $(36.9 \%)$ required mechanical ventilation during the study period, either in the ICU or at home, demonstrating the necessity for prolonged nursing to tracheostomy. In a survey in the UK, 933 children aged under 17 yrs received long term ventilation and $22 \%$ of them were tracheostomised [8]. Only $9 \%$ of all patients were treated in hospital units, while $91 \%$ were cared at home; these data emphasise the importance of the nursing support and educational aid at home in the management of tracheostomy in these patients. Also, in the Spanish survey educational support was provided in $79 \%$ of cases both in hospital and at home [13].

The duration of tracheostomy in mechanical ventilated children can depend on different factors, in particular underlying conditions, such as neuromuscular diseases or neurological conditions, cranial malformations, bronchopulmonary dysplasia, and the age of the patients. In the Spanish paper the duration of tracheostomy ranged from 1 day to $19 \mathrm{yrs}$, with a median duration of 34 months in children persistently tracheostomised during the 2-yr study period [13]. In 130 children (45.4\%) the intervention of tracheostomy was performed under 6 months of age, as a result of a condition predisposing to extubation failure and to tracheostomy [12]. In adults the duration of mechanical ventilation is lower than that observed in children, depending on different underlying diseases and on the use of early versus delayed intervention for tracheostomy. RUMBAK et al. [18] 
performed a study on 120 adults comparing those with an early tracheostomy (within $48 \mathrm{~h}$ ) to those with a delayed intervention (14-16 days), and they demonstrated that early tracheostomy appears correlated to a reduction in time of mechanical ventilation. The same results were obtained by FLAATTEN et al. [19] and by MÖLLER et al. [20].

With regard to tracheostomy-related complications in children, in older studies [21-23] data showed a complication rate of 20$40 \%, 2-3$ times higher than in adults [24], although in a recent study a decrease has been reported [25]. Complications are related to a prolonged cannulation period and persisting underlying conditions [8, 26]. The Spanish study showed complications in $46.9 \%$ of children: severe obstruction of tracheostomic cannula, infection related to tracheostomy and accidental decannulation were those most commonly observed [13]. To reduce the risk of local and general complications, different techniques to perform tracheostomy are used in adults, like percutaneous dilatational tracheostomy, still little used in children [27-29].

The mortality rate in tracheostomised children in the Spanish study is reported to be $12.5 \%$, only slightly lower than that reported by KOLLEF et al. [30] in adults with early tracheostomy; mortality rate is higher in severely ill patients. In recent years the improvement of technology in small children has reduced the risk of tracheostomy-related mortality, even in very low birth weight infants [10].

In conclusion, tracheostomy is widely performed in children, despite the advances of noninvasive mechanical ventilation. However, multicentre studies with large patients cohorts are lacking and some aspects of tracheostomy still under debate need to be clarified, for example whether, when and how to perform tracheostomy, and when to stop it.

PÉREZ-RUIZ et al. [13] contribute to keeping alive the interest on this ancient procedure still under debate.

\section{STATEMENT OF INTEREST}

None declared.

\section{REFERENCES}

1 Frost EA. Tracing the tracheostomy. Ann Otol Rhinol Laryngol 1976; 85: 618-624.

2 Colice GL. Historical perspective on the development of mechanical ventilation. In: Tobin MJ, ed. Principles and Practice of Mechanical Ventilation. New York, McGraw-Hill, 1994; pp. 1-35.

3 Pontoppidan H, Wilson RS, Rie MA, et al. Respiratory intensive care. Anesthesiology 1977; 47: 96-116.

4 Jackson C. Tracheotomy. Laryngoscope 1909; 19: 285-329.

5 MacIntyre NR, Cook DJ, Ely EW Jr, et al. Evidence-based guidelines for weaning and discontinuing ventilator support: a collective task force facilitated by the American College of Chest Physicians; the American Association for Respiratory Care; and the American College of Critical Care Medicine. Chest 2001; 120: 375-395.

6 Esteban A, Anzueto A, Alía I, et al. How is mechanical ventilation employed in the intensive care unit? An international utilization review. Am J Respir Crit Care Med 2000; 161: 1450-1458.

7 Groves DS, Durbin CG Jr. Tracheostomy in the critically ill: indications, timing and techniques. Curr Opin Crit Care 2007; 13: 90-97.
8 Wallis C, Paton JY, Beaton S, et al. Children on long-term ventilatory support: 10 years of progress. Arch Dis Child 2011; 96: 998-1002.

9 Al-Samri M, Mitchell I, Drummond DS, et al. Tracheostomy in children: a population-based experience over 17 years. Pediatr Pulmonol 2010; 45: 487-493.

10 Pereira KD, MacGregor AR, Mitchell RB. Complications of neonatal tracheostomy: a 5-year review. Otolaryngol Head Neck Surg 2004; 131: 810-813.

11 Trachsel D, Hammer J. Indications for tracheostomy in children. Paediatr Respir Rev 2006; 7: 162-168.

12 Baisch SD, Wheeler WB, Kurachek SC, et al. Extubation failure in pediatric intensive care incidence and outcomes. Pediatr Crit Care Med 2005; 6: 312-318.

13 Pérez-Ruiz E, Caro P, Pérez-Frías J, et al. Paediatric patients with a tracheostomy. A multicentre epidemiological study. Eur Respir J 2012; 40: 1502-1507.

14 Principi T, Morrison GC, Matsui DM, et al. Elective tracheostomy in mechanically ventilated children in Canada. Intensive Care Med 2008; 34: 1498-1502.

15 Lewis CW, Carron JD, Perkins JA, et al. Tracheotomy in pediatric patients: a national perspective. Arch Otolaryngol Head Neck Surg 2003; 129: 523-529.

16 Frutos-Vivar F, Esteban A, Apezteguia C, et al. Outcome of mechanically ventilated patients who require a tracheostomy. Crit Care Med 2005; 33: 290-298.

17 Albuali WH, Singh RN, Fraser DD, et al. Have changes in ventilation practice improved outcome in children with acute lung injury? Pediatr Crit Care Med 2007; 8: 324-330.

18 Rumbak MJ, Newton M, Truncale $\mathrm{T}$, et al. A prospective, randomized, study comparing early percutaneous dilational tracheotomy to prolonged translaryngeal intubation (delayed tracheotomy) in critically ill medical patients. Crit Care Med 2004; 32: 1689-1694.

19 Flaatten $\mathrm{H}$, Gjerde S, Heimdal JH, et al. The effect of tracheostomy on outcome in intensive care unit patients. Acta Anaesthesiol Scand 2006; 50: 92-98.

20 Möller MG, Slaikeu JD, Bonelli P, et al. Early tracheostomy versus late tracheostomy in the surgical intensive care unit. Am J Surg 2005; 189: 293-296.

21 Alladi A, Rao S, Das K, et al. Pediatric tracheostomy: a 13-year experience. Pediatr Surg Int 2004; 20: 695-698.

22 Kremer B, Botos-Kremer AI, Eckel HE, et al. Indications, complications, and surgical techniques for pediatric tracheostomies - an update. J Pediatr Surg 2002; 37: 1556-1562.

23 Puhakka HJ, Kero P, Valli $\mathrm{P}$, et al. Tracheostomy in pediatric patients. Acta Paediatr 1992; 81: 231-234.

24 Dulguerov P, Gysin C, Perneger TV, et al. Percutaneous or surgical tracheostomy: a meta-analysis. Crit Care Med 1999; 27: 1617-1625.

25 Palmieri TL, Jackson W, Greenhalgh DG. Benefits of early tracheostomy in severely burned children. Crit Care Med 2002; 30: 922-924.

26 Combes A, Luyt CE, Nieszkowska A, et al. Is tracheostomy associated with better outcomes for patients requiring long-term mechanical ventilation? Crit Care Med 2007; 35: 802-807.

27 Durbin CG Jr. Techniques for performing tracheostomy. Respir Care 2005; 50: 488-496.

28 Halum SL, Ting JY, Plowman EK, et al. A multi-institutional analysis of tracheotomy complications. Laryngoscope 2011; 122: $38-45$.

29 Raju A, Joseph DK, Diarra C, et al. Percutaneous versus open tracheostomy in the pediatric trauma population. Am Surg 2010; 76: 276-278.

30 Kollef MH, Ahrens TS, Shannon W. Clinical predictors and outcomes for patients requiring tracheostomy in the intensive care unit. Crit Care Med 1999; 27: 1714-1720. 